\title{
RNA interference of muscle actin and ATP synthase beta increases mortality of the phytoplasma vector Euscelidius variegatus
}

Running title: RNA interference effects on the phytoplasma vector Euscelidius variegatus

Simona Abbà ${ }^{*}$, Luciana Galetto ${ }^{*}$, Matteo Ripamonti ${ }^{*}$, Marika Rossi ${ }^{*}$ and Cristina Marzachi ${ }^{*}$

*Institute for Sustainable Plant Protection - National Research Council of Italy, IPSP-CNR, Strada delle Cacce 73, I-10135 Torino, Italy

† Dipartimento di Scienze Agrarie, Forestali ed Alimentari DISAFA, Università degli Studi di Torino, Largo Braccini 2, Grugliasco (TO), Italy

${ }^{\S}$ Corresponding author: phone: +39 0113977925; simona.abba@ipsp.cnr.it

Luciana Galetto: luciana.galetto@ipsp.cnr.it

Matteo Ripamonti: matteo.ripamonti@unito.it

Marika Rossi: marika.rossi@ipsp.cnr.it

Cristina Marzachì: cristina.marzachi@ipsp.cnr.it

\begin{abstract}
This article has been accepted for publication and undergone full peer review but has not been through the copyediting, typesetting, pagination and proofreading process which may lead to differences between this version and the Version of Record. Please cite this article as doi: $10.1002 /$ ps.5263
\end{abstract}


BACKGROUND: RNA interference (RNAi) techniques have emerged as powerful tools to develop novel management strategies for the control of insect pests. The leafhopper Euscelidius variegatus is a natural vector of chrysanthemum yellows phytoplasma and a laboratory vector of flavescence dorée phytoplasma. Phytoplasmas are insect-borne bacterial plant pathogens that cause economically relevant crop losses worldwide.

RESULTS: In the present study, we demonstrated that microinjection of muscle actin and ATP synthase $\beta$ dsRNAs in adult insects caused an exponential reduction in the expression of both genes, which began within 72 hours from the dsRNA administration and lasted for 14 days, leading to almost complete silencing of the target genes. Such silencing effects on muscle actin expression appeared to be both time- and dose-dependent. Our results also showed that the knockdown of both genes caused a significant decrease in survival rates in comparison with GFP dsRNA-injected control insects.

CONCLUSION: The effectiveness of RNAi-based gene silencing in $E$. variegatus guarantees the availability of a powerful reverse genetic tool for the functional annotation of its genes and the identification of those potentially involved in the interaction with phytoplasmas. In addition, this study demonstrated that muscle actin and ATP synthase $\beta$ may represent candidate genes for RNAi-based control of $E$. variegatus.

KEYWORDS: phytoplasma, RNAi, Euscelidius variegatus, actin, ATP synthase beta, microinjection

\section{INTRODUCTION}


Hemipteran insects are major vectors of plant-infecting pathogens that cause extensive crop damage and considerable economic losses. ${ }^{1-4}$ Aphids, psyllids, leafhoppers, planthoppers, and whiteflies are piercing-sucking insects that rely on the plant vascular system for their primary nutrient source. As a result of this feeding behaviour, they can inject plant viruses and bacteria through their saliva directly into the phloem or xylem, from where pathogens can spread throughout the plant and cause the disease. Despite the global threat posed by hemipteran insects to crop production, the massive use of pesticides is no longer a feasible counteraction to this growing menace, as public concerns are mounting over the effects of chemicals on the environment, non-target organisms and human health. A drastic reduction of the adverse effects arising from agricultural activities is an ambitious challenge that necessarily implies increasing investments in plant research with a dual objective: improving knowledge about the molecular basis of the tripartite interaction "insect vector - plant pathogen - host plant" and developing new sustainable biocontrol strategies to restrain pathogens multiplication and virulence in plants. In this regards, not only has RNA interference (RNAi) proved to be an efficient molecular tool for gene function determination, but also a very promising technique to develop target-specific and environmentally friendly methods for controlling insect pests and plant diseases. ${ }^{5-8}$ Since the discovery of the RNAi process in Caenorhabditis elegans, ${ }^{9}$ several experiments have successfully demonstrated that the administration of exogenously synthesized dsRNAs to eukaryotes triggers the degradation of homologous mRNAs, thereby modulating the level of the corresponding protein. Despite the tremendous potentiality of RNAi, there are at least two main challenges to the extensive use of dsRNAmediated gene silencing: the set-up of cost-effective and reliable methods for practical delivery of stable dsRNAs and the evaluation of the efficiency of the RNAi machinery. RNAi-mediated silencing 
effects, in fact, can vary greatly among insect species and also within the same insect species, depending on target genes, tissues in which target genes are expressed and life stage of insect (reviewed by Bellés ${ }^{10}$ ).

The leafhopper Euscelidius variegatus Kirshbaum (Hemiptera, Cicadellidae) is the natural vector of Chrysanthemum yellows phytoplasma (CYp), 'Candidatus Phytoplasma asteris' (16SrI-B), which is associated with a disease of ornamental plants in North-western Italy. ${ }^{11}$ The same insect is also used as a laboratory vector of Flavescence dorée (FD), ${ }^{12}$ an economically relevant quarantine disease of grapevine caused by a $16 \mathrm{SrV}$ phytoplasma.

Phytoplasma diseases, in general, are caused by cell wall-less, phloem-limited plant pathogenic bacteria that are associated with devastating damages to hundreds of plant species worldwide. ${ }^{13}$ Control of such diseases has so far been mainly based on the removal of infected plants and the application of insecticides, ${ }^{14}$ with consequent harmful effects on public and environmental health. Phytoplasma transmission is persistent and propagative, involving a latency period in the insect vector that ranges from days to months, during which the bacteria cross the gut barrier, circulate in the vector body and eventually reach the hemolymph and salivary glands before being transmitted to a new host plant. ${ }^{15,16}$ Detailed studies have shown that a latency period of about four weeks is required before E. variegatus can become infective and transmit CYp. ${ }^{17}$

The current understanding of pathogenicity mechanisms in vector-borne bacteria is largely influenced by the ability to culture those bacteria. ${ }^{18}$ However, phytoplasma are unculturable and, consequently, not amenable to conventional DNA manipulations. Such limitations have thus hampered studies on insect vectors and the molecular mechanisms at the basis of their interactions with phytoplasmas. In the 
present work, two E. variegatus genes potentially involved in the interaction with phytoplasmas, ${ }^{19}$ namely muscle actin and ATP synthase $\beta$, were chosen as RNAi targets. The effects of dsRNA microinjection on survival rates and silencing of target genes were evaluated to lay the basis for future functional studies on the disruption of phytoplasma-insect vector interactions by RNAi-mediated gene knockdown.

\section{MATERIALS AND METHODS}

\subsection{Insect rearing and RNA extraction}

E. variegatus isolate was originally collected in Piedmont (Italy) ${ }^{20}$ and continuously reared on oat, Avena sativa L., in growth chambers at $25^{\circ} \mathrm{C}$ and a photoperiod of $16: 8$ (L:D) h.

Total RNA was extracted from single adult insects using Direct-zol RNA Mini Prep Kit (Zymo Research, U.S.A). Briefly, each individual was crushed in $1.5 \mathrm{ml}$ tube with liquid nitrogen and a sterile micro-pestle, homogenized in TRI-Reagent $(500 \mu \mathrm{l})$, processed as described by manufacturer's instructions and finally eluted in DNAse/RNAse-free sterile water $(25 \mu 1)$. The optional step in-column DNAse treatment was also performed as detailed in Direct-zol procedure, to avoid DNA genomic contamination. RNA was analyzed in a Nanodrop ND-1000 spectophotometer to evaluate concentration, purity and quality of samples.

\subsection{Synthesis of dsRNAs}


The complete coding sequences of muscle actin and ATP synthase $\beta$ (target mRNAs) used in this work can be found in the TSA sequence database (BioProject: PRJNA393620) at NCBI under the accession numbers GFTU01006510.1 and GFTU01013594.1, respectively.

Fragments of the two target sequences were obtained from total RNA isolated from adult insects by RTPCR. The control template corresponding to a fragment of the gene sequence of green fluorescent protein (GFP) was PCR-amplified from plasmid pJL24. ${ }^{21,21}$ Primers used to generate the three dsRNA templates included the $\mathrm{T} 7$ promoter sequence at the 5 ' end (Table 1).

The three PCR products were then ligated into the pGEM-T Easy plasmid (Promega, U.S.A.) and plasmids were used as templates for the subsequent PCR reactions. The cloning step was performed to avoid cDNA synthesis every time that a new amount of template for the in vitro transcription was necessary. Then, one microgram of each column-purified PCR product was in vitro transcribed using the MEGAscript RNAi Kit (Thermo Fisher Scientific, U.S.A.) according to the manufacturer's instructions. After column-purification and elution in Tris-EDTA buffer (10 mM Tris-HCl, $0.1 \mathrm{mM}$ EDTA, pH 8.5), dsRNAs were quantified using a Nanodrop ND-1000 Spectrophotometer.

\section{3 dsRNA delivery}

According to the protocol optimized by Rashidi and colleagues, ${ }^{22}$ fifth instar nymphs of E. variegatus were starved for $2 \mathrm{~h}$, then artificially fed for $48 \mathrm{~h}$ on a liquid diet $(5 \%$ sucrose, $10 \mathrm{mM}$ Tris/Cl, $1 \mathrm{mM}$ EDTA, pH 8.0) pipetted between two layers of parafilm stretched over the top of truncated coneshaped plastic cages. For each experiment, six to 14 nymphs per cage were allowed to feed. At the end of artificial feeding, all live insects were transferred into plastic and nylon cages on oat plants for additional $24 \mathrm{~h}$. 
Newly emerged adults were anesthetized with $\mathrm{CO}_{2}$ and microinjected between two abdominal segments under a stereomicroscope using a fine glass needle connected to a Cell Tram Oil microinjector (Eppendorf, Germany). Insects were microinjected either with $1 \mu$ of filter sterilized Tris-EDTA buffer or with an equal volume of dsRNAs at three concentrations: $8 \mathrm{ng} / \mu 1,24 \mathrm{ng} / \mu \mathrm{l}$ or 80 ng/ $\mu 1$. Injected insects were then caged on oat plants and monitored daily till the end of the experiments. Dead insects were periodically removed.

\section{4 qRT-PCR and statistical analyses}

Quantitative reverse transcription PCR (qRT-PCR) was used to quantify the ability of the injected dsRNAs to knock down target mRNAs and an off-target mRNA. At least four biological replicates were analyzed at each time point for each dsRNA-injected or non-injected group. cDNA was synthesized from $1 \mu \mathrm{g}$ of total insect RNA using a High Capacity cDNA reverse transcription kit (Applied Biosystems, U.S.A.). The resulting cDNA was used as template of real time PCR reactions in a $10 \mu$ volume mix, containing 1x iTaq Universal Sybr Green Supermix (Bio-Rad) and $300 \mathrm{nM}$ of each primer. All the primer pairs used for qRT-PCR are listed in Table 1. Samples were run in duplicate in a CFX Connect Real-Time PCR Detection System (Bio-Rad, U.S.A.). Cycling conditions were: $95^{\circ} \mathrm{C}$ for $3 \mathrm{~min}$ and 40 cycles at $95^{\circ} \mathrm{C}$ for $30 \mathrm{sec}$ and $60^{\circ} \mathrm{C}$ for $1 \mathrm{~min}$ of annealing/extension step. The specificity of the PCR products was verified by melting curve analysis for all samples. No template controls were always included in each plate. Primers targeting glutathione S-transferase and elongation factor-1 $\alpha$ of E. variegatus were used as internal controls to normalize the cDNA among samples. The normalized expression levels of each target gene for each sample were calculated by CFX Maestro ${ }^{\mathrm{TM}}$ Software 
(Bio-Rad, U.S.A.). Expression stability of reference genes resulted acceptable in the multi-plate gene study.

Statistical differences in normalized expression levels were analyzed by the Wilcoxon rank sum test. Pvalues lower than 0.05 were considered statistically significant.

Kaplan-Meier curves were constructed to estimate the survival times (times-to-event) of each insect group, taking into account that, during the experiment, insects could have the event of interest (death) or be censored, i.e. taken out alive from the experiment at different time points to be used for expression analyses.

The log-rank (Mantel-Cox) test was used to establish whether there was a statistically significant difference $(p$-value $<0.05)$ between the survival curves of two experimental conditions. If significant differences occurred, the relative risk was calculated to quantitatively describe the difference between the survival times of two groups of insects.

All the statistical analyses described above were performed using the following R packages: Survival v. 2.38, Regression Modeling Strategies (rbs) v. 5.1-2 and Functions for Medical Statistics Book with some Demographic Data (fmsb) v. 0.6.3.

\section{RESULTS}

\subsection{Euscelidius variegatus RNAi machinery}

As a first step to understand whether a functional RNAi machinery exists in E. variegatus, its recently published transcriptome assembly was searched for ten genes involved in the three main insect RNAi pathways: ${ }^{23}$ Argonaute1, Dicer1, Loquacious, Drosha, and Pasha (involved in the miRNA pathway); 
Argonaute2, Dicer2, and R2D2 (involved in the siRNA pathway); Argonaute3 and Piwi (involved in the piRNA pathway) (Table S1). Tribolium castaneum genes were chosen as queries, as its genome was thoroughly surveyed for the genes that encode RNAi core components. ${ }^{24}$ Acyrthosiphon pisum homologs were also included in the comparison, as it is phylogenetically closer to E. variegatus and, more importantly, they have the same feeding habits (both are sap-sucker insects), which are known to influence the RNAi-response. ${ }^{8}$ The presence of all ten major RNAi pathway genes suggested that a potentially functional RNAi pathway is present in E. variegatus. The percentage of identity between $E$. variegatus and $T$. castaneum proteins were almost the same as those observed between E. variegatus and A. pisum, with the highest levels of protein identity (over 95\%) within Ago1 proteins (Fig. S1).

\subsection{Preliminary experiments with artificial feeding and microinjection}

Eight experiments were set up to determine the feasibility of oral dsRNA delivery to E. variegatus by artificial feeding. A maximum of 14 and a minimum of six synchronized fifth instar nymphs were fed for $48 \mathrm{~h}$ on artificial medium without dsRNAs and then transferred to cages with oat plants for $24 \mathrm{~h}$. The observed survival rate after $72 \mathrm{~h}$ varied widely: from $0 \%$ (all six caged nymphs died after $24 \mathrm{~h}$ ) to $50 \%$ (three of the six caged nymphs survived after three days), with no correlation to the initial number of artificially-fed insects (Table 2). Considering the extremely low and variable survival rate as well as the low number of insects that could be simultaneously trapped in each cage for artificial feeding, the adoption of an alternative dsRNA delivery approach became a priority. Thus, microinjection was attempted in the subsequent experiments. 
Microinjection was performed into newly emerged adults, because fifth instar nymphs were too small (less than $4 \mathrm{~mm}$ in length) and fragile to withstand the mechanical damage caused by needles. In two preliminary experiments, $\mathrm{CO}_{2}$-sedated adults were injected in the abdomen with $1 \mu \mathrm{l}$ of injection buffer and their survival rates were monitored daily for 7 days after the inoculation. No statistically significant difference (log-rank test, p-value $>0.05$ ) was observed between the survival rates of these two independent experiments. More importantly, the survival rate after 7 days was around $70 \%$ for both experiments, proving that, despite the trauma of injection, this technique ensured a better survival rate than artificial feeding (Table 2).

\subsection{Short-term effects of dsRNA microinjection on insect survival rates and expression levels of} muscle actin and ATP synthase $\beta$

In the first dsRNA injection experiments, two groups of 20 insects were injected with 80 ng muscle actin dsRNAs and GFP dsRNAs (control) and then monitored after 6, 24, 48 and 72 hours. No statistically significant difference (log-rank test, $\mathrm{p}$-value $>0.05$ ) was detected between the survival rates of the two populations (Table 3). Total RNA was extracted from the survived insects at $6 \mathrm{~h}, 24 \mathrm{~h}$, and $72 \mathrm{~h}$ after the injection and qRT-PCR was used to quantify the effects of dsRNAs injections on the expression of the muscle actin. The muscle actin dsRNA injections resulted in a statistically significant reduction $(66.8 \%$ reduction, Wilcoxon rank sum test, p-value $=0.04)$ in actin mRNA levels at 72 hours after the injection in comparison with the control (Fig. 1).

An analogous independent experiment was conducted with 80 ng ATP synthase $\beta$ and GFP dsRNAs. The results almost fully mirrored those obtained with actin dsRNAs. No statistically significant 
difference was, in fact, detected between the survival rates of the two insect populations (Table 3). On the other hand, a statistically significant reduction of ATP synthase $\beta$ transcription levels was observed after 24 hours $(55.0 \%$ reduction, Wilcoxon rank sum test, p-value $=0.029)$ and 72 hours $(71.8 \%$ reduction, $\mathrm{p}$-value $<0.01$ ) in ATP synthase $\beta$ dsRNA-injected insects in comparison with the control (Fig. 1).

These results implied that both muscle actin and ATP synthase $\beta$ dsRNAs had a time-dependent effect on the expression of the corresponding target genes.

\subsection{Medium-term effects of dsRNA microinjection}

The ultimate goal of this study was to lay the basis for future experiments to verify whether the knockdown of target genes significantly alters the insect acquisition efficiency of phytoplasmas.

Considering that a) according to the previous experiment, a reduction in the expression of dsRNA target genes is detected at the latest around the third day after injection and b) at least one day is generally required for an efficient phytoplasma acquisition by $E$. variegatus, ${ }^{22}$ the knockdown of target genes should last at least eight days to test their possible involvement during phytoplasma acquisition. Therefore, in the new experiment the observation time was extended to 14 days to evaluate the persistence of silencing effects during the potential latency period after the phytoplasma acquisition.

Three groups of 35 insects were daily observed: muscle actin and ATP synthase $\beta$ dsRNA-injected insects as target-specific groups and GFP dsRNA-injected insects as controls. Again, although the survival distributions of the three insect populations evolved differently, the log-rank test revealed that muscle actin and ATP synthase $\beta$ dsRNAs did not have statistically significant effects on insect 
survival rates (Fig. 2A, Table S2). Despite that, a conspicuous drop in survival rates was observed in muscle actin and ATP synthase $\beta$ dsRNA-injected insects at 12 days post-injection (dpi), leading to final survival rates of $23.4 \% \pm 9.7$ and $31.5 \% \pm 17.5$, respectively (Fig. 2A). In GFP dsRNA-injected insects the final survival rate was instead $54.9 \% \pm 17.0$ (Fig. 2A).

From 4 dpi on, muscle actin and ATP synthase $\beta$ dsRNA-injected insects showed a statistically significant decrease (Wilcoxon rank sum test, p-value <0.05) in target mRNA levels in comparison with the controls (Fig. 2B-2C), with a final 97.5\% reduction in the expression of both target genes. Such over-time decrease in muscle actin and ATP synthase $\beta$ expression levels could be both described by exponential functions (muscle actin: $y=6.0819 \mathrm{e}^{-1.076 \mathrm{x}}$, ATP synthase $\beta$ : $\mathrm{y}=1.4952 \mathrm{e}^{-0.746 x}$ ) with a high coefficient of determination $\left(\mathrm{R}^{2} \sim 0.9\right)$ (Fig. 2B-C). The equations of the interpolating functions indicated that a) the expression of both target genes decreased at a rate proportional to their expression value at each time point and b) expression levels of muscle actin decreased with a faster rate than those of ATP synthase $\beta$. By contrast, in GFP dsRNA-injected controls the expression of both target genes just fluctuated over time without a specific pattern (Fig. 2B-C).

\subsection{Checking possible off-target gene silencing on cytoplasmic actin}

During RNA-seq analysis of E. variegatus transcriptome, ${ }^{25}$ a fragment of the cytoplasmic actin transcript was identified. The alignment of the muscle actin fragment used as dsRNA template with the known sequence of the cytoplasmic actin revealed that the two sequences share $82.5 \%$ identity over a 321 bp-long region (Fig. S2A). Consequently, insects injected with muscle actin dsRNAs and GFP dsRNAs were also analyzed to verify the possibility of an off-target silencing of the cytoplasmic actin. 
Actually, muscle actin dsRNA-injected insects did not show any statistically significant difference in cytoplasmic actin mRNA levels, either at 4 dpi or 8 dpi (Fig. S2B), compared to the controls. Therefore, the possibility of any off-target silencing effects on the cytoplasmic actin was excluded.

\subsection{Survival rates of dsRNA-injected insects over a 27-day period}

A third experiment was conducted adding a group of non-injected insects to the three groups of 35 insects injected with muscle actin, ATP synthase $\beta$ and GFP dsRNAs. The daily count of survivors was further extended till the death of all insects of at least one group. Obtaining a good survival rate after four weeks from the microinjection would have given us the possibility of monitoring the effects of gene knockdown also on the transmission efficiency of phytoplasmas. At 27 dpi (nearly four weeks), muscle actin dsRNA-injected insects were all dead and only three surviving insects were counted in the ATP synthase $\beta$ dsRNA-injected group (Fig. 3, Table S3). When comparing survival rates obtained during this experiment to those of the mid-term experiment at common time points, some fluctuations were observed. In the mid-term experiment both target-specific dsRNA-injected insects reached $50 \%$ of survival (median survival) at day 12, whereas in this experiment muscle actin dsRNA-injected insects reached the median survival at day 13 and ATP synthase $\beta$ dsRNA-injected insects at day 9. Despite that, if survival rates at $14 \mathrm{dpi}$ had been considered as ending points, no statistically significant difference (log-rank test, p-value $>0.05$ ) would have been observed between GFP and target-specific dsRNAs-injected insects even in this experiment. Only by comparing the survival curves over the whole 27 day-period, a statistically significant decrease was observed between target-specific dsRNAsinjected insects and GFP dsRNA-injected insects (log-rank test, p-value $<0.01$ ), but not between the 
two groups injected with target-specific dsRNAs. In addition, survival rates observed in all three dsRNAs-injected groups were significantly reduced (log-rank test, p-value $<0.01$ ) compared to that of non-injected insects. At $21 \mathrm{dpi}$, for example, survival rates were: $13.1 \% \pm 7.01$ for ATP synthase $\beta$ dsRNA-injected insects, $14.3 \% \pm 5.91$ for muscle actin dsRNA-injected insects, $53.7 \% \pm 8.58$ for GFP dsRNA-injected insects and 92.3\% \pm 5.23 for non-injected insects. Such differences were highlighted also by the calculation of the relative risk: dsRNA-injected insects were at least 5.8 times (GFP control) as likely to die as non-injected insects.

\subsection{Modulation of RNAi responses by different concentrations of muscle actin dsRNAs}

The high mortality observed in the long-term experiment, especially of insects injected with muscle actin dsRNAs, required further experiments to define the optimal effective concentration for future experiments with phytoplasmas. Thus, 20 insects were injected with one tenth (8 ng/insect) and one third (24 ng/insect) of the dsRNA concentration used in the previous experiments. Overall no statistically significant differences (log-rank test, $\mathrm{p}$-value $>0.05$ ) were recorded in survival rates between GFP and muscle actin dsRNAs-injected insects at both concentrations, although a drastic drop occurred again around 13 dpi in response to muscle actin dsRNAs only (Fig. 4A, Table S4). In general, during the first two weeks, survival rates of actin dsRNA-injected insects were higher than in previous experiments: e.g. at 14 dpi survival rates of insects injected with $24 \mathrm{ng}$ and $8 \mathrm{ng}$ of muscle actin dsRNAs were nearly 46\%, whereas those of insects injected with 80 ng were around 25\%. By contrast, at 21 dpi survival rates at the three concentrations were similar: $11.5 \% \pm 10.2$ with $24 \mathrm{ng} / \mathrm{insect}$ dsRNAs and $19.0 \% \pm 11.0$ with 8 ng/insect dsRNAs. As regards the silencing effects, statistically 
significant decreases (Wilcoxon rank sum test, p-value $<0.05$ ) were detected at 7 and 14 dpi at both concentrations, compared to the corresponding GFP controls (Fig. 4B). The reduction of the expression levels at both time points was proportional to the quantities of injected dsRNAs. As a whole, these results demonstrated that dsRNAs inhibited muscle actin gene expression also in a dose-dependent manner.

\section{DISCUSSION}

dsRNA administration has been shown to be an effective and consistent way to induce RNAi in numerous insect species, including some hemipteran vectors of plant-infecting bacteria: Diaphorina citri and Bactericera cockerelli, both vectors of Candidatus Liberibacter spp., ${ }^{26-28}$ Homalodisca vitripenni, vector of Xylella fastidiosa, ${ }^{29}$ and Circulifer haematoceps, vector of Spiroplasma citri.$^{30}$ To our knowledge, RNA interference assays have never been attempted on a phytoplasma vector before the current investigation. As a first step, we took advantage of the recently published E. variegatus transcriptome assembly ${ }^{25}$ to perform an in silico identification of the genes coding for the major components of RNAi machinery, including Dicers, Argonauts, R2D2, and ribonuclease III enzymes. Nevertheless, the presence of all the RNAi core genes is not a guarantee of successful suppression of gene expression, as there are many elements that strongly affect the efficiency of gene silencing in Hemiptera (reviewed by Li and colleagues ${ }^{5}$ ). Three main factors were taken into account in this study: the target gene, the length of dsRNAs, and the delivery method. In a previous work, E. variegatus ATP synthase $\beta$ and muscle actin were demonstrated to interact with the immunodominant membrane protein Amp of CYp. ${ }^{19}$ Given their possible involvement in phytoplasma transmission, the 
corresponding genes were selected as primary targets for the experimental setup of dsRNA-mediated gene silencing in E. variegatus. The possibility of comparing each target gene against the E. variegatus transcriptomic database can make the design of templates for dsRNA synthesis extremely specific and reliable, minimizing unwanted off-target effects. In our study, a BLASTn analysis of the ATP synthase $\beta$ transcript did not reveal any significant similarity (expected value $>1 \mathrm{e}^{-5}$ ) with any other insect transcripts, whereas the muscle actin transcript showed a high percentage of nucleotide identity with a fragment of the cytoplasmic actin coding sequence. Despite that, the template for muscle actin dsRNAs was designed on this region to evaluate the occurrence of possible off-target silencing effects. Contrary to expectations, no off-target silencing effects were observed. This result confirmed the hypothesis of Birmingham and colleagues ${ }^{31}$ that the level of overall sequence identity, except for nearperfect matches, is a poor predictor of off-targeted genes.

The length of dsRNAs administered to E. variegatus ranged from 375 bp (GFP) to 469 bp (ATP synthase $\beta$ ), which was perfectly within the average range (185 bp - $675 \mathrm{bp}$ ) of most dsRNA sequences used in RNAi experiments involving Hemiptera. ${ }^{5}$

Methods for dsRNA delivery into Hemiptera include microinjection, artificial diet and feeding with bacteria/plant/viruses/fungi that express dsRNAs. ${ }^{32}$ dsRNA delivery through expression in planta is likely to be the most efficient method for the in field application of RNAi techniques in piercingsucking insects, but the process requires huge amounts of dsRNAs and their delivery into the plant vascular tissues where they feed. ${ }^{33,34}$ Given such technical difficulties, this approach was not considered suitable to test for the first time the efficiency of the RNAi machinery in E. variegatus. Thus, we opted for dsRNA delivery by artificial diet and by microinjection. An artificial feeding 
protocol for E. variegatus was previously developed to demonstrate the involvement of the CYp Amp protein in the phytoplasma transmission process. ${ }^{22}$ Despite that, the high mortality rate recorded in the present study, even without the administration of dsRNAs, indicated that this approach does not represent an efficient option for reverse genetic studies in this insect. Conversely, microinjection, although more delicate and time-consuming, resulted in survival rates sufficient to measure the effects of dsRNAs delivery. Another advantage of this technique is that the exact amount of dsRNA brought into the experimental organism is known, thereby ensuring high repeatability of measurements between different experiments.

Besides their specific role in E. variegatus as possible interactors with phytoplasma membrane proteins, in general muscle actin and ATP synthase $\beta$ play important roles in cell viability. Actin is the major contractile component in myofibrils of muscle cells and ATP synthase $\beta$ is part of the multisubunit enzyme F1-Fo ATP synthase, which uses the proton gradient generated by the respiratory chain to synthesize ATP. Due to their key roles in cell metabolism, their RNAi-mediated knockdown has been shown to cause an increase in the mortality rate of injected insects and/or a delay in larval development. $^{28,29,35,36}$ In our experiments, the mortality rate of insects injected with $80 \mathrm{ng}$ of target dsRNAs showed a marked increase around 12 dpi and reached critical levels at $21 \mathrm{dpi}$, when only one seventh of the injected insects could survive. Despite that, the percentages of surviving insects before 12 dpi should be sufficient to conduct future experiments on the efficiency of phytoplasma acquisition following the silencing of the two genes. In the case of muscle actin, microinjection of $24 \mathrm{ng}$ of dsRNAs could increase the number of insects available for the acquisition experiments, because the survival rate before 12 dpi was higher than the one observed with the administration of $80 \mathrm{ng}$ of 
dsRNAs, while the silencing effects on muscle actin were similar. Instead, microinjection of $8 \mathrm{ng}$ of muscle actin dsRNAs at the same time point resulted in lower silencing effects on the target genes than those caused by the two higher concentrations. No macroscopic phenotypic alteration was observed in the injected insects.

The RNAi effects on both target mRNAs appeared to be time-dependent, as expression levels followed an exponential decrease pattern over time. The silencing of both genes could still be observed 14 days after microinjection. Such long duration of the RNAi effects could be explained by the high stability of the template dsRNA, as it was observed in honeybees after intra-abdominal injection. ${ }^{37}$ Another mechanism, thoroughly described in C. elegans and in plants, would imply the existence of RNA dependent RNA polymerases (RdRPs) that catalyze the amplification of dsRNAs. However, RdRPs were not identified in any of the insect genomes available so far. ${ }^{8}$ Therefore, if an amplification mechanism exists in insects, it should occur via a different and unknown pathway.

Furthermore, silencing of muscle actin appeared to be also dose-dependent, as it increased in response to increasing dsRNA concentrations.

Finally, the fact that few, if any, insects survived four weeks after the injection of target-specific dsRNAs will make future experiments on phytoplasma transmission efficiency very cumbersome, unless the initial number of injected insects will be markedly increased. Over the four-week period, we also observed an unexpected increase in the mortality rate of GFP dsRNA-injected insects compared to the non-injected population, even if GFP dsRNAs were not expected to trigger any response. The occurrence of RNAi responses caused by GFP dsRNAs was reported also for other insects, such as Apis mellifera ${ }^{38}$ and B. Cockerelli. ${ }^{28}$ In honeybees, in particular, it was demonstrated that GFP 
dsRNAs causes large-scale changes in the expression of genes associated with multiple biological processes. ${ }^{38}$ In our case, similar deleterious off-target silencing effects and/or a saturation of the RNAi pathway with consequent cytotoxicity could be hypothesized.

\section{CONCLUSION}

The impossibility to culture phytoplasmas has so far hindered understanding of the molecular mechanisms of vector colonization. To date, the only way to study in vivo phytoplasma interactions with their hemipteran vectors is to apply reverse genetic tools to insect hosts. Consequently, the demonstration of the effectiveness of RNAi-based gene silencing in E. variegatus guarantees the availability of a powerful molecular tool to improve the functional annotation of its genes and identify those potentially involved in the interaction with phytoplasmas. Such an achievement is likely to lay the basis for most intriguing goals, such as the development of new strategies for the control of phytoplasmosis by silencing the insect genes involved in the processes of bacterial acquisition and transmission. In addition, RNAi could be also used to simply decrease the survival rate of the insect vector. Although dsRNA microinjection is not suitable for large-scale application and additional «search on delivery, safety, and off-target effect is still to be done, muscle actin and ATP synthase $\beta$ were, in fact, identified as good targets for future attempts at limiting the spread of this plant disease.

\section{ACKNOWLEDGEMENTS}


The authors thank Marta Vallino for critical discussion and Piero Caciagli for expert assistance in statistical analyses. They also thank Mattia Pegoraro and Giulia Molinatto for the help in insect microinjection. This work was funded by Fondazione Cassa di Risparmio di Torino, Torino (Italy) in the framework of the project Siglofit, Richieste Ordinarie 2016, Richiesta n. 51249 (RF=2016-0577).

\section{References}

1 Gottwald TR, da Graça JV and Bassanezi RB, Citrus Huanglongbing: The Pathogen and Its Impact. Plant Health Progress:online (2007).

2 Munyaneza JE, Zebra Chip Disease of Potato: Biology, Epidemiology, and Management. American Journal of Potato Research 89:329-350 (2012).

3 Orlovskis Z, Canale MC, Thole V, Pecher P, Lopes JR and Hogenhout SA, Insect-borne plant pathogenic bacteria: getting a ride goes beyond physical contact. Current Opinion in Insect Science 9:16-23 (2015).

4 Panizzi AR, Growing Problems with Stink Bugs (Hemiptera: Heteroptera: Pentatomidae): Species Invasive to the U.S. and Potential Neotropical Invaders. American Entomologist 61:223-233 (2015).

5 Li J, Wang X, Wang M, Ma W and Hua H, Advances in the use of the RNA interference technique in Hemiptera. Insect Science 20:31-39 (2013).

$6 \mathrm{Gu} \mathrm{L}$ and Knipple DC, Recent advances in RNA interference research in insects: Implications for future insect pest management strategies. Crop Protection 45:36-40 (2013).

7 Kanakala S and Ghanim M, RNA Interference in Insect Vectors for Plant Viruses. Viruses 8:329 (2016).

8 Joga MR, Zotti MJ, Smagghe G and Christiaens O, RNAi Efficiency, Systemic Properties, and Novel Delivery Methods for Pest Insect Control: What We Know So Far. Front Physiol 7:553 (2016).

9 Fire A, Xu S, Montgomery MK, Kostas SA, Driver SE and Mello CC, Potent and specific genetic interference by double-stranded RNA in Caenorhabditis elegans. Nature 391:806-811 (1998).

10 Bellés X, Beyond Drosophila: RNAi In Vivo and Functional Genomics in Insects. Annu Rev Entomol 55:111-128 (2009). 
11 Conti M and Mela L, Il giallume della margherita (Chrysanthemum frutescens), micoplasmosi tipica della riviera ligure. La Difesa delle Piante 10:171-178 (1987).

12 Caudwell A, Kuszala C, Larrue J and Bachelier J, Transmission de la Flavescence dorée de la feve a la feve par des cicadelles des genres Euscelis et Eusceliditis. Intervention possible de ces insectes dans l'epidemiologie du bois noir en Bourgogne. Annales de Phytopathologie Hors série:181-189 (1972).

13 Maejima K, Oshima K and Namba S, Exploring the phytoplasmas, plant pathogenic bacteria. Journal of General Plant Pathology 80:210-221 (2014).

14 Hogenhout SA, Oshima K, Ammar ED, Kakizawa S, Kingdom HN and Namba S, Phytoplasmas: bacteria that manipulate plants and insects. Molecular Plant Pathology 9:403-423 (2008).

15 Lefol C, Lherminier J, Boudon-Padieu E, Larrue J, Louis C and Caudwell A, Propagation of Flavescence dorée MLO (Mycoplasma-like Organism) in the Leafhopper Vector Euscelidius variegatus Kbm. Journal of Invertebrate Pathology 63:285-293 (1994).

16 Moya-Raygoza G and Nault LR, Transmission Biology of Maize Bushy Stunt Phytoplasma by the Corn Leafhopper (Homoptera: Cicadellidae). Annals of the Entomological Society of America 91:668-676 (1998).

17 Bosco D, Galetto L, Leoncini P, Saracco P, Raccah B and Marzachi C, Interrelationships between "Candidatus Phytoplasma asteris" and its leafhopper vectors. J Econ Entomol 100:1504-1511 (2007).

18 Perilla-Henao LM and Casteel CL, Vector-Borne Bacterial Plant Pathogens: Interactions with Hemipteran Insects and Plants. Front Plant Sci 7:1163 (2016).

19 Galetto L, Bosco D, Balestrini R, Genre A, Fletcher J and Marzachi C, The Major Antigenic Membrane Protein of "Candidatus Phytoplasma asteris" Selectively Interacts with ATP Synthase and Actin of Leafhopper Vectors. PLoS One 6:e22571 (2011).

20 Bosco D, Minucci C, Boccardo G and Conti M, Differential acquisition of chrysanthemum yellows phytoplasma by three leafhopper species. Entomologia Experimentalis et Applicata 83:219-224 (1997).

21 Lindbo JA, TRBO: A High-Efficiency Tobacco Mosaic Virus RNA-Based Overexpression Vector. Plant Physiol 145:1232-1240 (2007).

22 Rashidi M, Galetto L, Bosco D, Bulgarelli A, Vallino M, Veratti F and Marzachì C, Role of the major antigenic membrane protein in phytoplasma transmission by two insect vector species. BMC Microbiology 15:1-12 (2015). 
23 Dowling D, Pauli T, Donath A, Meusemann K, Podsiadlowski L, Petersen M, Peters RS, Mayer C, Liu S, Zhou X, Misof B and Niehuis O, Phylogenetic Origin and Diversification of RNAi Pathway Genes in Insects. Genome Biol Evol 8:3784-3793 (2016).

24 Tomoyasu Y, Miller SC, Tomita S, Schoppmeier M, Grossmann D and Bucher G, Exploring systemic RNA interference in insects: a genome-wide survey for RNAi genes in Tribolium. Genome Biology 9:R10 (2008).

25 Galetto L, Abbà S, Rossi M, Vallino M, Pesando M, Arricau-Bouvery N, Dubrana MP, Chitarra W, Pegoraro M, Bosco D and Marzachì C, Two Phytoplasmas Elicit Different Responses in the Insect Vector Euscelidius variegatus Kirschbaum. Infect Immun 86:e00042-18 (2018).

26 El-Shesheny I, Hajeri S, El-Hawary I, Gowda S and Killiny N, Silencing Abnormal Wing Disc Gene of the Asian Citrus Psyllid, Diaphorina citri Disrupts Adult Wing Development and Increases Nymph Mortality. PLoS One 8:e65392 (2013).

27 Hajeri S, Killiny N, El-Mohtar C, Dawson WO and Gowda S, Citrus tristeza virus-based RNAi in citrus plants induces gene silencing in Diaphorina citri, a phloem-sap sucking insect vector of citrus greening disease (Huanglongbing). Journal of Biotechnology 176:42-49 (2014).

28 Wuriyanghan H, Rosa C and Falk BW, Oral Delivery of Double-Stranded RNAs and siRNAs Induces RNAi Effects in the Potato/Tomato Psyllid, Bactericerca cockerelli. PLoS One 6:e27736 (2011).

29 Rosa C, Kamita SG and Falk BW, RNA interference is induced in the glassy winged sharpshooter Homalodisca vitripennis by actin dsRNA. Pest Manag Sci 68:995-1002 (2012).

30 Eliautout R, Dubrana M-P, Vincent-Monégat C, Vallier A, Braquart-Varnier C, Poirié M, Saillard $\mathrm{C}$, Heddi A and Arricau-Bouvery N, Immune response and survival of Circulifer haematoceps to Spiroplasma citri infection requires expression of the gene hexamerin. Developmental \& Comparative Immunology 54:7-19 (2016).

1 Birmingham A, Anderson EM, Reynolds A, Ilsley-Tyree D, Leake D, Fedorov Y, Baskerville S, Maksimova E, Robinson K, Karpilow J, Marshall WS and Khvorova A, 3' UTR seed matches, but not overall identity, are associated with RNAi off-targets. Nature Methods 3:199-204 (2006).

32 Christiaens O and Smagghe G, The challenge of RNAi-mediated control of hemipterans. Current Opinion in Insect Science 6:15-21 (2014).

33 Scott JG, Michel K, Bartholomay L, Siegfried BD, Hunter WB, Smagghe G, Zhu KY and Douglas AE, Towards the elements of successful insect RNAi. J Insect Physiol 59:1212-1221 (2013). 
34 Hunter WB, Glick E, Paldi N and Bextine BR, Advances in RNA interference: dsRNA Treatment in Trees and Grapevines for Insect Pest Suppression. Southwestern Entomologist 37:85-87 (2012).

35 Upadhyay SK, Chandrashekar K, Thakur N, Verma PC, Borgio JF, Singh PK and Tuli R, RNA interference for the control of whiteflies (Bemisia tabaci) by oral route. Journal of Biosciences 36:153-161 (2011).

36 Cancino-Rodezno A, Lozano L, Oppert C, Castro JI, Lanz-Mendoza H, Encarnación S, Evans AE, Gill SS, Soberón M, Jurat-Fuentes JL and Bravo A, Comparative Proteomic Analysis of Aedes aegypti Larval Midgut after Intoxication with Cry11Aa Toxin from Bacillus thuringiensis. PLoS One 7:e37034 (2012).

37 Amdam GV, Simões ZLP, Guidugli KR, Norberg K and Omholt SW, Disruption of vitellogenin gene function in adult honeybees by intra-abdominal injection of double-stranded RNA. BMC Biotechnology 3:1 (2003).

38 Nunes MF, Aleixo CA, Barchuk RA, Bomtorin DA, Grozinger MC and Simões ZLP, Non-Target Effects of Green Fluorescent Protein (GFP)-Derived Double-Stranded RNA (dsRNA-GFP) Used in Honey Bee RNA Interference (RNAi) Assays. Insects 4:90-103 (2013).

39 Galetto L, Bosco D and Marzachì C, Selection of reference genes from two leafhopper species challenged by phytoplasma infection, for gene expression studies by RT-qPCR. BMC Research Notes 6:409 (2013). 
Table 1 List of primers used in this work. T7 promoter sequence is underlined.

\begin{tabular}{|c|c|c|c|c|}
\hline Application & Primer name & 52-32sequences & Target gene & $\begin{array}{c}\text { Product } \\
\text { size }\end{array}$ \\
\hline \multirow{4}{*}{ synthesis } & Eva_T7actinf & TAATACGACTCACTATAGGTGCTGGACTCTGGTGACGG & \multirow[t]{2}{*}{ Muscle actin } & \multirow{2}{*}{$375 \mathrm{nt}$} \\
\hline & Eva_T7actinfr & TAATACGACTCACTATAGCTCGTGGATACCGCAGGATT & & \\
\hline & $\begin{array}{c}\text { Eva_T7ATPsyn } \\
\text { Betaf }\end{array}$ & TAATACGACTCACTATAGTACGGCCAGATGAACGAGCC & \multirow{2}{*}{ ATP synthase } & \multirow{2}{*}{$469 \mathrm{nt}$} \\
\hline & $\begin{array}{c}\text { Eva_T7ATPsyn } \\
\text { Betar }\end{array}$ & TAATACGACTCACTATAGGGACACCACGAGCAATGTTG & & \\
\hline \multirow{2}{*}{$>$} & T7GFPf & TAATACGACTCACTATAGCTTTTCACTGGAGTTGTCCC & \multirow{2}{*}{ GFP } & \multirow{2}{*}{$403 \mathrm{nt}$} \\
\hline & T7GFPr & TAATACGACTCACTATAGGTTTGTGTCCGAGAATGTTTC & & \\
\hline 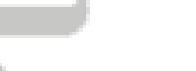 & ActFw832 $2^{\dagger}$ & AAGGACCTGTACGCCAACAC & \multirow{2}{*}{ Muscle actin } & \multirow{2}{*}{$190 \mathrm{nt}$} \\
\hline & $\operatorname{ActRv} 1021^{\dagger}$ & GCTGGAAGGTGGACAGAGAG & & \\
\hline \multirow{4}{*}{$\begin{array}{l}\text { Recl time } \\
\text { PCR }\end{array}$} & ActCytF_204 & AAAGTCCTACGAACTGCCTGAT & \multirow{2}{*}{$\begin{array}{l}\text { Cytoplasmic } \\
\text { actin }\end{array}$} & \multirow{2}{*}{$124 \mathrm{nt}$} \\
\hline & ActCytR_327 & GGTGGTCTCGTGGATGCCGCAA & & \\
\hline & $\mathrm{ATP}^{2} \mathrm{Fw} 622^{\dagger}$ & CGCTTTACTCAGGCTGGTTC & \multirow{2}{*}{ ATP synthase } & \multirow{2}{*}{$171 \mathrm{nt}$} \\
\hline & $\mathrm{ATP}^{2} \operatorname{Rv} 792^{\dagger}$ & GTCATCAGCTGGCACGTAGA & & \\
\hline & $\mathrm{EF} 1- \pm \_F 215^{\S}$ & CCATCGACATTGCCCTGTGG & \multirow{2}{*}{$\begin{array}{l}\text { elongation } \\
\text { factor- } 1 \pm\end{array}$} & \multirow{2}{*}{$111 \mathrm{nt}$} \\
\hline & EF1-士_R325 & CCTGTGAGGTTCCAGTGATCATG & & \\
\hline & GST1_F257 & CCAAGGACCCCAAGAAGCGA & \multirow{2}{*}{$\begin{array}{l}\text { glutathione S- } \\
\text { transferase }\end{array}$} & \multirow{2}{*}{$113 \mathrm{nt}$} \\
\hline & GST1_R369 & TGGCGCTCCTCCAAACATCA & & \\
\hline
\end{tabular}

${ }^{\dagger}$ Primers were described in Galetto and colleagues $(2013)^{39}$

$\mathrm{CR}$ parameters of primers targeting cytoplasmic actin were: $92 \%$ reaction efficiency, $0.989 \mathrm{R}^{2}$, $85,5^{\circ} \mathrm{C}$ melting peak

$\S$ Primers were described in Galetto and colleagues $(2018)^{25}$ 
Table 2 Survival rates observed during the preliminary (without dsRNAs) artificial feeding and microinjection experiments. Column 1: kind of experiment (artificial feeding or microinjection); Column 2: initial number of insects that were artificially fed or microinjected; Column 3: artificially fed insects and microinjected insects were monitored over a period of three and seven days, respectively, but tables report only the days in which insect deaths were recorded and the final day of the experiment; Column 4: number of surviving insects at each time point; Column 5 : percentages of surviving insects at each time point; Column 6: standard errors referred to the survival percentages. NaN: not applicable.

\begin{tabular}{|c|c|c|c|c|c|}
\hline Group & Number of insects & $\begin{array}{c}\text { Time } \\
\text { (days) }\end{array}$ & $\begin{array}{c}\text { Number of } \\
\text { surviving } \\
\text { insects } \\
\end{array}$ & $\begin{array}{c}\text { Survival } \\
(\%)\end{array}$ & $\begin{array}{l}\text { Standard } \\
\text { error }(\%)\end{array}$ \\
\hline \multirow{3}{*}{ Artificial feeding 1} & \multirow{3}{*}{7} & 1 & 5 & 71 & 17 \\
\hline & & 2 & 4 & 57 & 19 \\
\hline & & 3 & 3 & 43 & 19 \\
\hline \multirow{2}{*}{ Artificial feeding 2} & \multirow{2}{*}{6} & 1 & 4 & 67 & 19 \\
\hline & & 3 & 3 & 50 & 2 \\
\hline \multirow{2}{*}{ Artificial feeding 3} & \multirow{2}{*}{6} & 1 & 0 & 0 & $\mathrm{NaN}$ \\
\hline & & 3 & 0 & 0 & $\mathrm{NaN}$ \\
\hline \multirow{3}{*}{ Artificial feeding 4} & \multirow{3}{*}{7} & 1 & 5 & 71 & 17 \\
\hline & & 2 & 4 & 57 & 19 \\
\hline & & 3 & 2 & 29 & 17 \\
\hline \multirow{3}{*}{ Artificial feeding 5} & \multirow{3}{*}{10} & 1 & 6 & 60 & 16 \\
\hline & & 2 & 5 & 50 & 16 \\
\hline & & 3 & 4 & 40 & 16 \\
\hline \multirow{2}{*}{ Artificial feeding 6} & \multirow{2}{*}{10} & 1 & 6 & 60 & 16 \\
\hline & & 3 & 5 & 50 & 16 \\
\hline \multirow{3}{*}{ Artificial feeding 7} & \multirow{3}{*}{11} & 1 & 5 & 46 & 15 \\
\hline & & 2 & 4 & 36 & 15 \\
\hline & & 3 & 3 & 27 & 13 \\
\hline \multirow{3}{*}{ Artificial feeding 8} & \multirow{3}{*}{14} & 1 & 9 & 64 & 13 \\
\hline & & 2 & 7 & 50 & 13 \\
\hline & & 3 & 4 & 29 & 12 \\
\hline \multirow{4}{*}{ Microinjection 1} & \multirow{4}{*}{50} & 1 & 42 & 84 & 5 \\
\hline & & 2 & 39 & 78 & 6 \\
\hline & & 3 & 38 & 76 & 6 \\
\hline & & 7 & 38 & 76 & 6 \\
\hline \multirow{2}{*}{ Microinjection 2} & \multirow{2}{*}{27} & 1 & 24 & 89 & 6 \\
\hline & & 3 & 22 & 82 & 7 \\
\hline
\end{tabular}




\begin{tabular}{llll}
4 & 21 & 78 & 8 \\
\hline 5 & 20 & 74 & 8 \\
\hline 7 & 19 & 70 & 9 \\
\hline
\end{tabular}

This article is protected by copyright. All rights reserved. 
Table 3 Survival rates observed over a 72-hour period during microinjection experiments with $80 \mathrm{ng} / \mu 1$ dsRNAs. Column 1: name of the target gene (GFP stands for green fluorescent protein, ACTINm for muscle actin and ATPsynbeta for ATP synthase $\beta$ ); Column 2: target of injected dsRNAs; Column 3: initial number of dsRNA-injected insects; Column 4: survival of dsRNA-microinjected insects was monitored for 72 hours, but table reports only time points at which insect deaths were recorded and the final day of the experiment; Column 5: number of surviving insects at each time point; Column 6: percentages of surviving insects at each time point; Column 7: standard errors referred to the survival percentages.

\begin{tabular}{|c|c|c|c|c|c|c|}
\hline Experiment & Group & $\begin{array}{c}\text { Number of } \\
\text { injected } \\
\text { insects }\end{array}$ & $\begin{array}{l}\text { Time } \\
\text { (hours) }\end{array}$ & $\begin{array}{l}\text { Number of } \\
\text { surviving } \\
\text { insects }\end{array}$ & $\begin{array}{c}\text { Survival } \\
(\%)\end{array}$ & $\begin{array}{l}\text { Standard } \\
\text { error }(\%)\end{array}$ \\
\hline \multirow{4}{*}{ ACTINm } & \multirow{2}{*}{ dsGFP } & \multirow{2}{*}{19} & 24 & 18 & 95 & 5 \\
\hline & & & 72 & 18 & 95 & 5 \\
\hline & \multirow{2}{*}{ dsACTINm } & \multirow{2}{*}{21} & 24 & 19 & 90 & 6 \\
\hline & & & 72 & 19 & 90 & 6 \\
\hline \multirow{5}{*}{ ATPsynbeta } & \multirow{2}{*}{ dsGFP } & \multirow{2}{*}{18} & 24 & 17 & 94 & 5 \\
\hline & & & 72 & 17 & 94 & 5 \\
\hline & \multirow{3}{*}{ dsATPsynbeta } & \multirow{3}{*}{19} & 24 & 18 & 95 & 5 \\
\hline & & & 48 & 17 & 83 & 12 \\
\hline & & & 72 & 17 & 83 & 12 \\
\hline
\end{tabular}


Supporting information Table S1. Names and NCBI accession numbers of the genes involved in the three main insect RNAi pathways. N/A: not annotated

\begin{tabular}{|l|l|l|l|}
\hline Gene names & Tribolium castaneum & Acyrtosiphon pisum & Euscelidius variegatus \\
\hline Ago1 & XP_008196651.1 & CCD31673.1 & GFTU01004640.1 \\
\hline Ago2 & $\begin{array}{l}\text { NP_001107842.1, } \\
\text { XP_008192985.1 }\end{array}$ & XP_016662198.1 & GFTU01008426.1 \\
\hline Ag03 & XP_968053.2 & XP_016656024.1 & GFTU01016377.1 \\
\hline Dicer1 & XP_008199045.1 & XP_001944314.2 & GFTU01004888.1 \\
\hline Dicer2 & NP_001107840.1 & N/A & GFTU01010822.1 \\
\hline Drosha & XP_008199088.1 & XP_003247913.1 & GFTU01002931.1 \\
\hline Loquacious & XP_008198431.1 & XP_016657757.1 & GFTU01010148.1 \\
\hline Pasha & XP_971282.1 & XP_001947403.1 & GFTU01010211.1 \\
\hline piwi & XP_008196303.1 & XP_001949977 & GFTU01014046.1 \\
\hline R2D2 & NP_001128425.1 & NP_001155644.1 & GFTU01005523.1 \\
\hline
\end{tabular}

${ }^{\dagger}$ Euscelidius variegatus accession numbers are referred to TSA sequence database (BioProject: PRJNA393620)

${ }^{\ddagger}$ partial sequences

This article is protected by copyright. All rights reserved. 
Supporting information Table S2. Survival rates observed daily over a 14-day period during microinjection experiments of 35 insects for each group with 80ng/ $\mu \mathrm{l}$ dsRNAs. Column 1: kind of injected dsRNAs (GFP stands for green fluorescent protein, ACTINm for muscle actin and ATPsynbeta for ATP synthase ${ }^{2}$ ); Column 2: survival of dsRNA-microinjected insects was monitored for 14 days, but table reports only time points at which insect deaths were recorded and the final day of the experiment; Column 3: percentages of surviving insects at each time point; Column 4: standard errors referred to the survival percentages.

\begin{tabular}{|c|c|c|c|}
\hline Group & $\begin{array}{c}\text { Time } \\
\text { (days) }\end{array}$ & Survival (\%) & $\begin{array}{l}\text { Standard } \\
\text { error (\%) }\end{array}$ \\
\hline \multirow{5}{*}{ dsGFP } & 1 & 93 & 3.9 \\
\hline & 4 & 82.4 & 6.1 \\
\hline & 6 & 78.5 & 6.9 \\
\hline & 12 & 73.2 & 8.2 \\
\hline & 14 & 54.9 & 17.0 \\
\hline \multirow{9}{*}{ dsACTINm } & 1 & 91.8 & 3.5 \\
\hline & 4 & 77.4 & 5.5 \\
\hline & 5 & 72.6 & 6.2 \\
\hline & 6 & 70.1 & 6.4 \\
\hline & 7 & 67.2 & 6.7 \\
\hline & 8 & 64.3 & 7.1 \\
\hline & 12 & 29.2 & 10.2 \\
\hline & 13 & 23.4 & 9.7 \\
\hline & 14 & 23.4 & 9.7 \\
\hline \multirow{5}{*}{ dsATPsynbeta } & 1 & 90.7 & 4.4 \\
\hline & 4 & 82.7 & 6.0 \\
\hline & 6 & 78.8 & 6.9 \\
\hline & 12 & 47.3 & 17.7 \\
\hline & 14 & 31.5 & 17.5 \\
\hline
\end{tabular}


Supporting information Table S3. Survival rates observed daily over a 27-day period during microinjection experiments of 35 insects for each group with $80 \mathrm{ng} / \mu \mathrm{l} \mathrm{dsRNAs}$. Column 1: kind of injected dsRNAs (GFP stands for green fluorescent protein, ACTINm for muscle actin and ATPsynbeta for ATP synthase ${ }^{2}$ ) and control (Non-injected); Column 2: survival of dsRNA-microinjected insects was monitored for 27 days, but table reports only time points at which insect deaths were recorded and the final day of the experiment; Column 3: percentages of surviving insects at each time point; Column 4: standard errors referred to the survival percentages. NaN: not applicable.

\begin{tabular}{|c|c|c|c|}
\hline Group & $\begin{array}{c}\text { Time } \\
\text { (days) }\end{array}$ & Survival (\%) & $\begin{array}{l}\text { Standard } \\
\text { error }(\%)\end{array}$ \\
\hline \multirow{9}{*}{ dsGFP } & 1 & 97.2 & 2.7 \\
\hline & 2 & 91.7 & 4.6 \\
\hline & 6 & 72.2 & 7.5 \\
\hline & 8 & 69.4 & 7.7 \\
\hline & 13 & 66.3 & 8.0 \\
\hline & 16 & 63.1 & 8.2 \\
\hline & 20 & 53.7 & 8.6 \\
\hline & 23 & 50.5 & 8.6 \\
\hline & 27 & 41.0 & 8.6 \\
\hline \multirow{12}{*}{ dsACTINm } & 1 & 97.1 & 2.8 \\
\hline & 2 & 91.4 & 4.7 \\
\hline & 6 & 82.9 & 6.4 \\
\hline & 8 & 60.0 & 8.3 \\
\hline & 9 & 54.3 & 8.4 \\
\hline & 13 & 40.0 & 8.3 \\
\hline & 14 & 28.6 & 7.6 \\
\hline & 16 & 17.1 & 6.4 \\
\hline & 17 & 14.3 & 5.9 \\
\hline & 23 & 8.6 & 4.7 \\
\hline & 24 & 5.7 & 3.9 \\
\hline & 27 & 0 & $\mathrm{NaN}$ \\
\hline \multirow{8}{*}{ dsATPsynbeta } & 1 & 92.6 & 5.0 \\
\hline & 2 & 88.9 & 6.1 \\
\hline & 3 & 81.5 & 7.5 \\
\hline & 6 & 74.1 & 8.4 \\
\hline & 9 & 47.9 & 10.2 \\
\hline & 10 & 39.2 & 10.0 \\
\hline & 13 & 30.5 & 9.5 \\
\hline & 14 & 17.4 & 7.9 \\
\hline
\end{tabular}




\begin{tabular}{llll}
\hline & 20 & 13.1 & 7.0 \\
\cline { 2 - 4 } & 27 & 13.1 & 7.0 \\
\hline \multirow{3}{*}{ Non-injected } & 10 & 96.2 & 3.8 \\
\cline { 2 - 4 } & 17 & 92.3 & 5.2 \\
\cline { 2 - 4 } & 27 & 92.3 & 5.2 \\
\hline
\end{tabular}


Supporting information Table S4. Survival rates observed daily over a 21-day period during microinjection experiments of 20 insects for each group with $8 \mathrm{ng} / \mu \mathrm{l}$ and $24 \mathrm{ng} / \mu \mathrm{l}$ dsRNAs. Column 1 : kind of injected dsRNAs and concentration (GFP stands for green fluorescent protein and ACTINm for muscle actin); Column 2: survival of dsRNA-microinjected insects was monitored for 21 days, but table reports only time points at which insect deaths were recorded and the final day of the experiment; Column 6: percentages of surviving insects at each time point; Column 7: standard errors referred to the survival percentages

\begin{tabular}{|c|c|c|c|}
\hline Group & $\begin{array}{l}\text { Time } \\
\text { (days) }\end{array}$ & Survival (\%) & $\begin{array}{l}\text { Standard } \\
\text { error }(\%)\end{array}$ \\
\hline \multirow{6}{*}{ 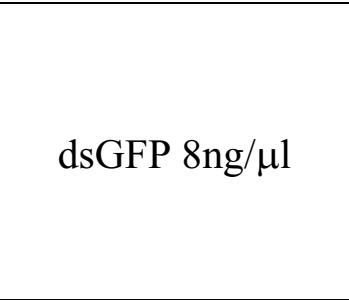 } & 1 & 93 & 3.9 \\
\hline & 4 & 82.4 & 6.1 \\
\hline & 6 & 78.5 & 6.9 \\
\hline & 12 & 73.2 & 8.2 \\
\hline & 14 & 54.9 & 17.0 \\
\hline & 21 & 54.9 & 17.0 \\
\hline \multirow{12}{*}{ dsACTINm $8 \mathrm{ng} / \mu \mathrm{l}$} & 1 & 84.8 & 6.2 \\
\hline & 2 & 78.8 & 7.1 \\
\hline & 3 & 75.8 & 7.5 \\
\hline & 6 & 63.6 & 8.4 \\
\hline & 7 & 60.6 & 8.5 \\
\hline & 8 & 56.6 & 8.9 \\
\hline & 10 & 51.9 & 9.2 \\
\hline & 14 & 47.6 & 9.4 \\
\hline & 15 & 38.1 & 11.4 \\
\hline & 16 & 28.6 & 11.9 \\
\hline & 17 & 19.0 & 11.1 \\
\hline & 21 & 19.0 & 11.1 \\
\hline \multirow{11}{*}{ dsGFP $24 n g / \mu l$} & 2 & 97.0 & 4.6 \\
\hline & 3 & 90.9 & 5.5 \\
\hline & 6 & 73.3 & 8.1 \\
\hline & 7 & 64.2 & 9.3 \\
\hline & 10 & 45.8 & 10.2 \\
\hline & 14 & 34.4 & 12.5 \\
\hline & 15 & 22.9 & 12.5 \\
\hline & 16 & 11.5 & 10.3 \\
\hline & 21 & 11.5 & 10.3 \\
\hline & 1 & 93.3 & 4.6 \\
\hline & 3 & 90.0 & 5.5 \\
\hline
\end{tabular}




\begin{tabular}{lccc}
\hline dsACTINm 24 ng/ $\mu 1$ & 6 & 73.3 & 8.1 \\
\cline { 2 - 4 } & 10 & 64.2 & 9.3 \\
\cline { 2 - 4 } & 14 & 45.8 & 10.2 \\
\cline { 2 - 4 } & 16 & 34.4 & 12.5 \\
\cline { 2 - 4 } & 21 & 22.9 & 12.5 \\
\hline
\end{tabular}


Figure 1 Relative expression levels of muscle actin and ATP synthase $\beta$ measured after the injection with $80 \mathrm{ng}$ of dsRNAs. Total RNA was extracted at 6, 24 and 72 hours post-injection from adult insects and analyzed by qRT-PCR using the primers described in Table 1. For each time point the first couple of histograms represents muscle actin expression levels in insects injected with GFP dsRNAs (dsGFP [ACTINm]) and muscle actin dsRNAs (dsACTINm); the second couple represents ATP synthase $\beta$ expression levels in insects injected with GFP dsRNAs (dsGFP [ATPsynbeta]) and ATP synthase $\beta$ dsRNAs (dsATPsynbeta). Asterisks indicate statistically significant differences $(\mathrm{P}<0.05$; Wilcoxon rank sum test). Error bars represent standard error of the mean expression value for each treatment.

Figure 2 Effects caused by microinjections of $80 \mathrm{ng}$ of dsRNAs over a 14-day period. (A) Survival rates of E. variegatus after microinjection with GFP dsRNAs (dsGFP), muscle actin dsRNAs (dsACTINm, purple) and ATP synthase $\beta$ dsRNAs (dsATPsynbeta). (B-C) Relative expression levels of muscle actin and ATP synthase $\beta$. Total RNA was extracted at 1, 4, 6, 8 and 14 post-injection. For each time point the first couple of histograms represents muscle actin expression levels in insects injected with GFP dsRNAs (dsGFP [ACTINm]) and muscle actin dsRNAs (dsACTINm); the second couple represents ATP synthase $\beta$ expression levels in insects injected with GFP dsRNAs (dsGFP TPsynbeta]) and ATP synthase $\beta$ dsRNAs (dsATPsynbeta). Asterisks indicate statistically significant differences $(\mathrm{P}<0.05$; Wilcoxon rank sum test). Error bars represent standard error of the mean expression value for each treatment. The equations of the curves that interpolate the expression data of muscle actin and ATP synthase $\beta$ are reported. 
Figure 3 Survival rates over a 27-day period after microinjection of $80 \mathrm{ng}$ of dsRNAs. Survival rates of non-injected insects (non-injected) and insects injected with GFP dsRNAs (dsGFP), muscle actin dsRNAs (dsACTINm) and ATP synthase $\beta$ dsRNAs (dsATPsynbeta).

Figure 4 Effects caused by microinjections of $8 \mathrm{ng}$ and $24 \mathrm{ng}$ of dsRNAs. (A) Survival rates of $E$. variegatus over a 21-day period after microinjection with $8 \mathrm{ng}$ of GFP dsRNAs (dsGFP 8ng/insect), 8 ng of muscle actin dsRNAs (dsACTINm 8ng/insect), 24 ng of GFP dsRNAs (dsGFP 24ng/insect) and $24 \mathrm{ng}$ of muscle actin dsRNAs (dsACTINm 24ng/insect). (B) Relative expression levels of muscle actin. Total RNA was extracted at 7 and 14 days post-injection. For each time point the first couple of histograms represents expression levels in insects injected with 8 ng of GFP dsRNAs (dsGFP 8ng/insect) and $8 \mathrm{ng}$ of muscle actin dsRNAs (dsACTINm 8ng/insect); the second couple of histograms represents expression levels in insects injected with 24 ng of GFP dsRNAs (dsGFP 24ng/insect) and 24 ng of muscle actin dsRNAs (dsACTINm 24ng/insect). Asterisks indicate statistically significant differences $(\mathrm{P}<0.05$; Wilcoxon rank sum test). Error bars represent standard error of the mean expression value for each treatment.

Supporting information Figure S1 Percentages of sequence identities between E. variegatus RNAi pathway proteins and the corresponding proteins from Tribolium castaneum and Acyrthosiphon pisum. See Supporting Information Table S1 for gene names and accession numbers.

Supporting Information Figure S2 Evaluating possible off-target effects of muscle actin dsRNAs on cytoplasmic actin expression levels (A) alignment of the muscle actin fragment used as dsRNA 
template with the known sequence of the cytoplasmic actin. The two sequences share $82.5 \%$ identity (asterisks) over a 321bp-long region. (B) Relative expression levels of cytoplasmic actin. Total RNA was extracted at 4 and 8 days post-injection. Green and purple indicate cytoplasmic actin expression levels in insects injected with $80 \mathrm{ng}$ of GFP dsRNAs (dsGFP) and $80 \mathrm{ng}$ of muscle actin dsRNAs (dsACTINm), respectively. Error bars represent standard error of the mean expression value for each treatment. 


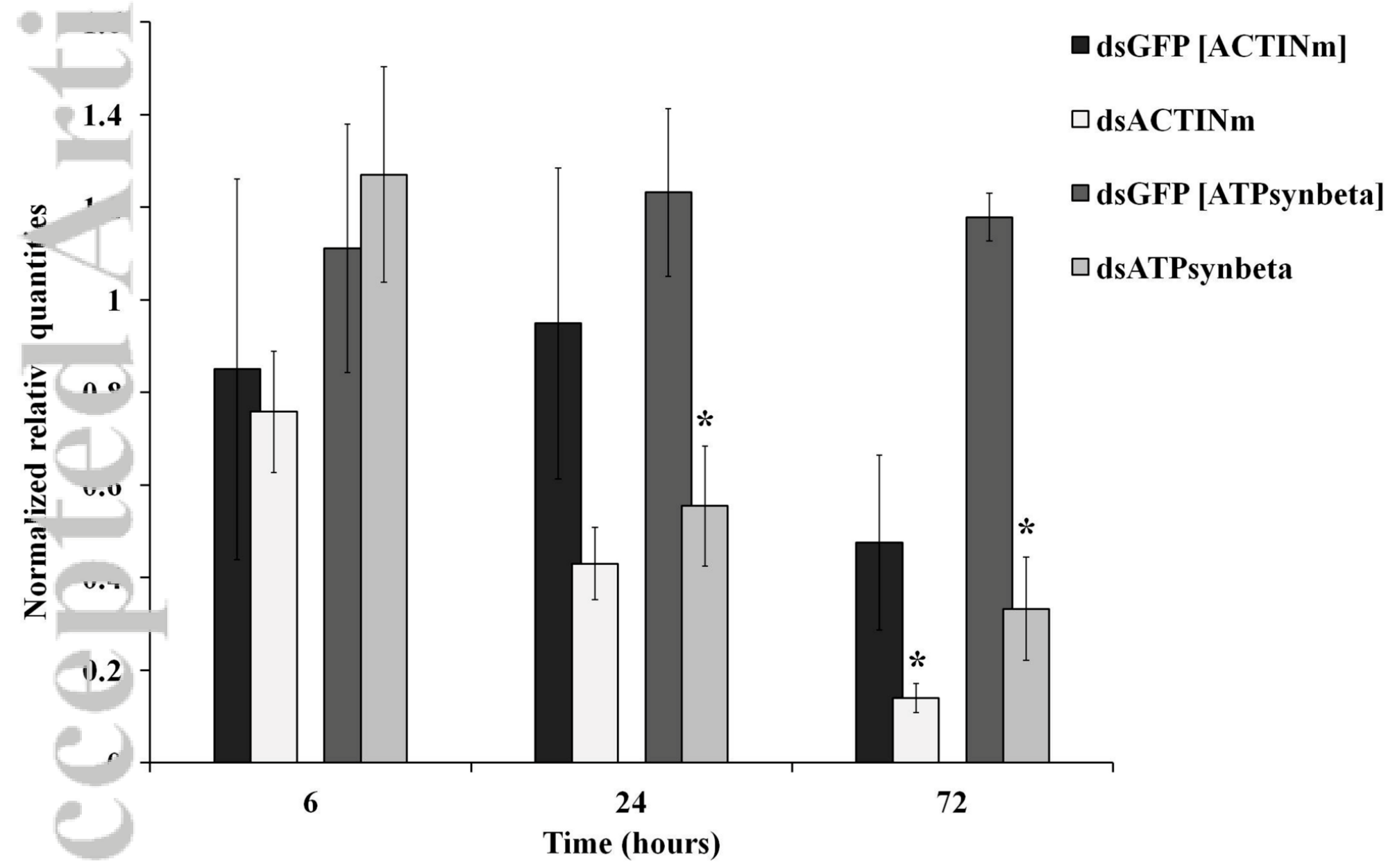

Figure_1.png 


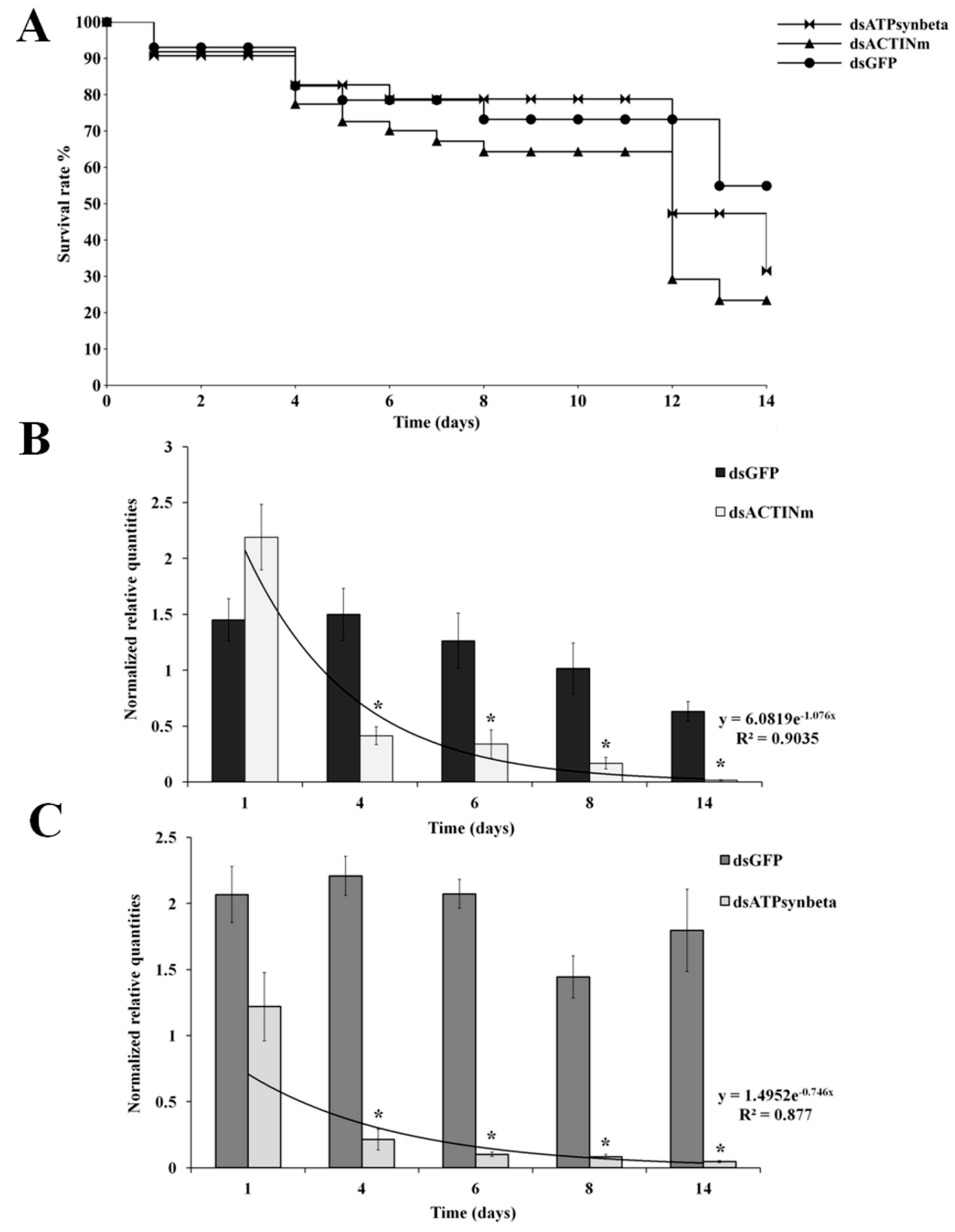

Figure_2.png 


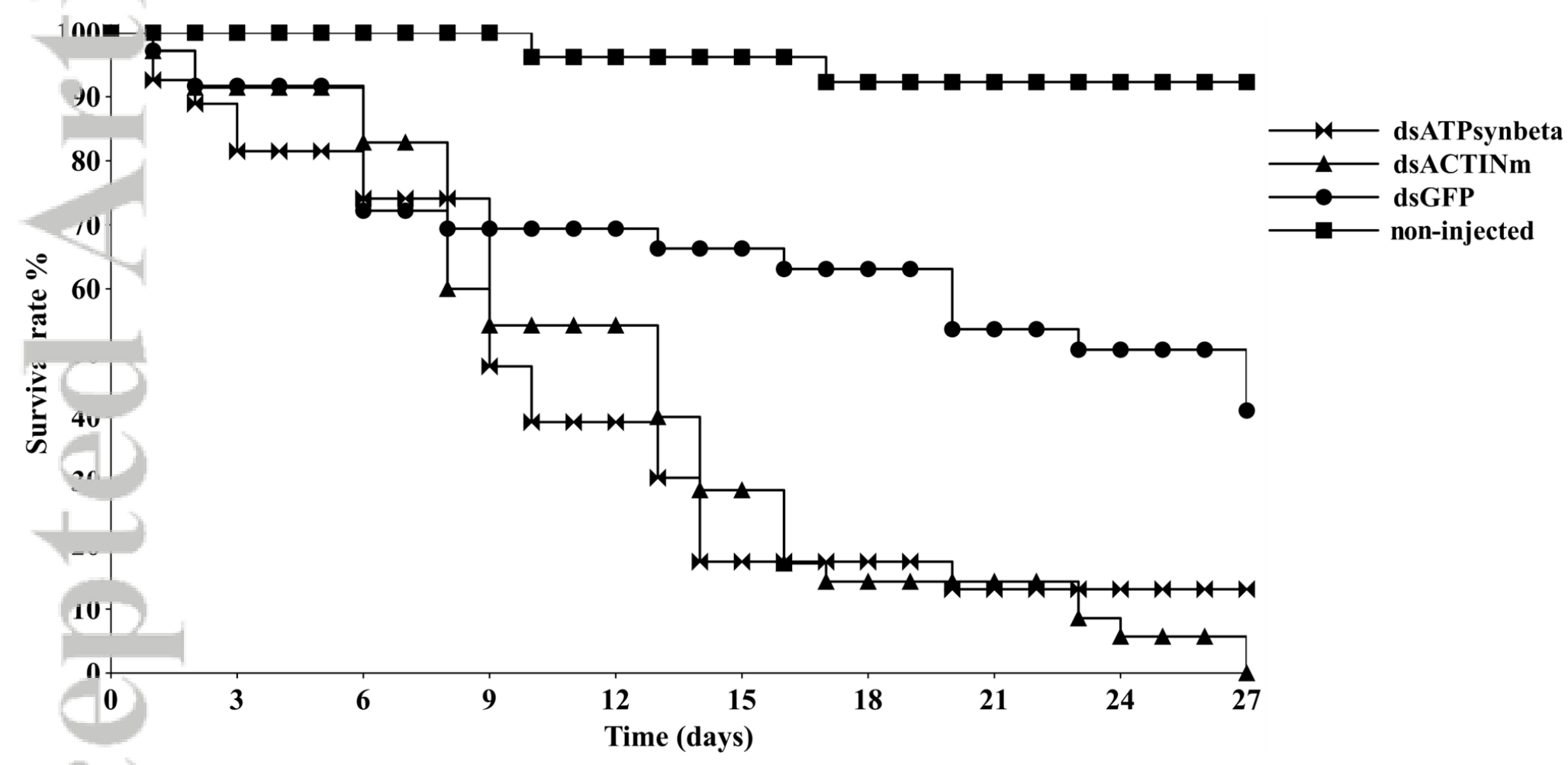

Figure_3.png 
A

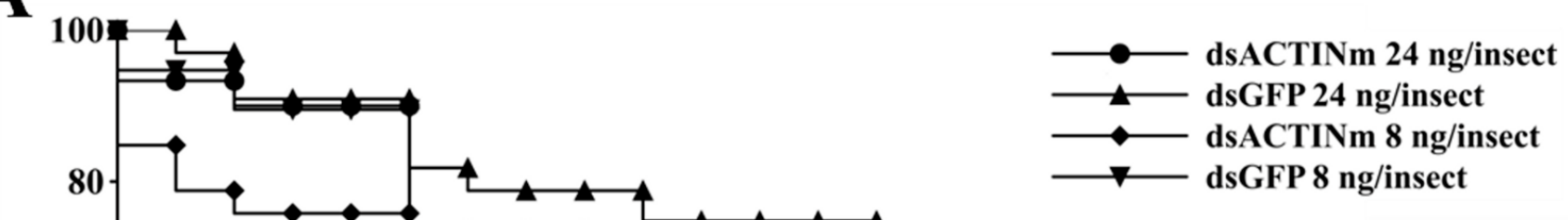

B

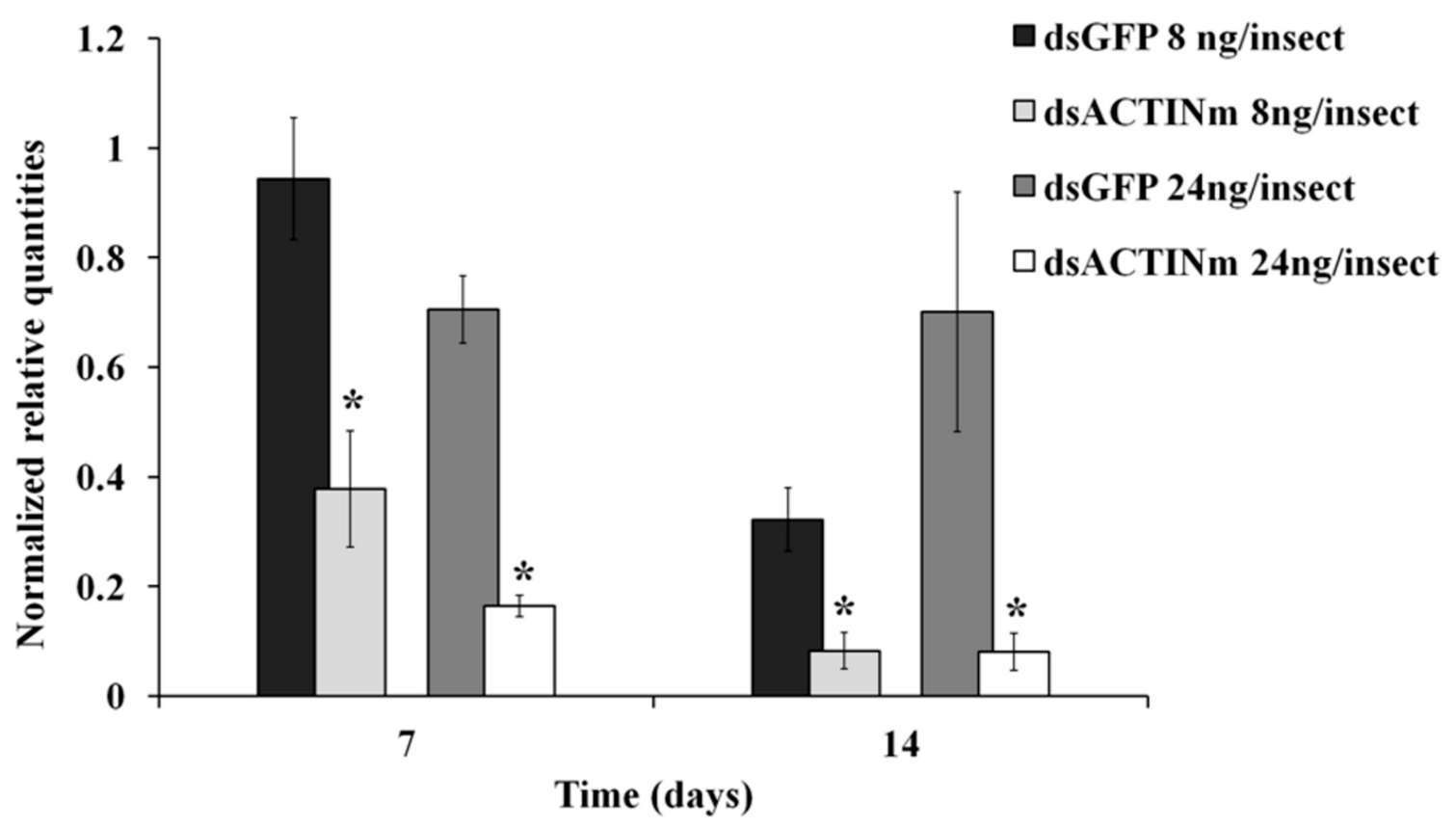

Figure_4.png 